\title{
Influence of Poloxmer on the Dissolution Properties of Mosapride and Its Pharmaceutical Tablet Formulation
}

\author{
Takwa E. Ellakwa1, Alaa Fahmy ${ }^{2 *}$ and Doha E. Ellakwa ${ }^{3}$ \\ ${ }^{1}$ Physical Chemistry Department, Egyptian Russian University, ${ }^{2}$ Chemistry \\ Department, Faculty of Science and ${ }^{3}$ Biochemistry Department, Faculty of Pharmacy \\ (Girls), Al-Azhar University11884 Cairo, Egypt.
}

\begin{abstract}
$\mathrm{T}$ HIS WORK was an attempt to improve therapeutic efficacy and increase patient compliance thereby formulating immediate release of Mosapride citrate's tablets with improved physical and chemical characteristics. The tablet form was prepared by wet granulation of Mosapride with a binder solution of Poloxmer 407 and compressed the dried granules of Mosapride into non-friable, stable tablets. The other objective, the performance of two classes of superdisintegrants as croscarmellose sodium (AcDi-Sol), and sodium starch glycolate (Primojel) in dissolution of Mosapride immediate release and promoting disintegration tablets was evaluated. The post-compression and the pre-compression parameters were characterized which within their respective standards must lie. Chemical composition and crystallinity were investigated via FTIR and XRD, respectively. The post compression parameters such as thickness test, hardness, friability testes and in vitro drug release studies were also performed.
\end{abstract}

Keywords: Dissolution enhancement, Croscarmellose sodium, Mosapride, Poloxmer, Sodium starch glycolate.

\section{Introduction}

For the therapeutic effect of drugs the solubility and dissolution are the most important parameters. To achieve desired concentration of drugs, solubility is the important parameter in the systemic circulation for pharmacological response[1] . The scientists used various approaches such as micronization, salt formation, solid dispersions, polymers' complexion, $\mathrm{pH}$ alteration; drug derivatization, nanonization, addition of surfactants to improve the dissolution of drugs which were poorly water soluble[2,3]. For example, all techniques of solid dispersion method have proved to be the most simple and economical one to improve the bioavailability and dissolution of poor water soluble drugs[4].

By using super disintegrates, further enhancement of dissolution can be done[5]. Mosapride is a novel pro-kinetic agent. It seems to exert its action by a high affinity and specify for 5-HT4 receptor. Additionally, the principal metabolite has proved to be potent 5-HT3 antagonist and high affinity to receptors. Mosapride has been utilized to treat chronic gastritis, gastro-esophageal reflux disease, nonulcer dyspepsia and diabetic gastropathy[6] .

In the pharmaceutical industry, it is commonly recognized that more than $40 \%$ of all newly developed drugs are poorly soluble or insoluble in water [7]. As an absorption enhancer surfactant acts therefore both dissolution and permeability of the drug increases. The dissolution rate is enhanced using suitable surfactants for promoting wetting and penetration of dissolution fluid into the drug particles. For solubility enhancement both ionic and nonionic surfactants were used. Among the solubility of cationic surfactants is lower than anionic one [8] .

For the preparation of dispersions of poor water soluble drugs different water soluble carriers were employed. The most common carriers were used polyethylene glycols, $\beta$ - cyclodextrin, polyvinyl 
pyrrolidine and hydroxylpropyl-methylcellulose. Recently, pluronics or poloxamers, has been exploited. They are a group of block copolymers and are used in pharmaceutical formulation of incapable water soluble drugs. Poloxamer (PXM) consists of hydrophobic core (poly propylene) and hydrophilic polyoxyethylene chain arranged in a tri-block structure for giving an amphiphilic structure. The hydrophobic drug may be solubilized within the core or conjugated to the micelle forming polymer to improve the dissolution of unable water soluble drugs. These polymers as solubilizing agents, wetting agents, emulsifiers, and stabilizers in pharmaceutical formulations are widely used [3,9]. In this work attempts were made to improve the dissolution of Mosapride using a solid dispersion technology. Solid dispersion (SD), compounds are dispersed into water-soluble carriers, and they have been generally utilized to increase the dissolution properties and the bioavailability of poorly soluble drugs in water. The physicochemical characterization of dispersion was done to evaluate the chemical interaction between the polymer and drug. Additionally, improving the solubility of poorly water soluble drug (Mosapride citrate dehydrates) using surfactants and formulating into immediate release tablets utilizing super disintegrants was discussed.

\section{Experimental}

\section{Materials}

All pharmacy eutical grade material was bought from Pharmaceutical suppliers. Mosapride citrate dihydrate (active drug) (98.0\% $-102.0 \%$ pure, as required in the USA Pharmacopoeial Forum) was purchased from Hetero Drugs Limited (India). Poloxamer 407 was bought from BASFthe Chemical Co. (Ludwigshafen, Germany), Sodium starch glycolate, Microcrystalline cellulose (Avicel PH 101), Microcrystalline cellulose (Avicel PH 102), talc, crosscarmelose sodium, colloidal silicon dioxide (aerosil 200) were bought from international specialty products (Germany).

\section{Preparation of mosapride tablets}

The tablets were prepared by wet granulation.

\section{Wet granulation}

Poloxamer 407 is dissolved in purified water and the total quantity of mosapride citrate dihydrate was added with stirring until complete solubility. The Poloxamer/mosapride solution is<smiles>CCOc1cc(N)c(Cl)cc1C(=O)NCC1CN(Cc2ccc(F)cc2)CCO1</smiles><smiles>CC(O)COC(C)(C)CC(C)OC(C)C</smiles>

Fig. 1. a. Mosapride citrate salt dihydrate (4-Amino5-chloro-2-ethoxy-N-[[4-[(4 fluorophenyl) methyl] -2-morpholinyl] methyl] benzamide citrate dihydrate), b. Poloxamer 407 (Poly (ethylene glycol) -block-poly (propylene glycol)-block-poly(ethylene glycol)).

added to Avicel PH 101with mixing. The final wet granulate is dried in a fluid bed dryer at $55-60^{\circ} \mathrm{C}$ and checking to loss of drying (LOD) less than $2.0 \%$, then granules were sieved through a No. 12 Mesh screen. After that they were taken into a mini drum blender along with the Avicel PH 102, sodium starch glycolate, crosscarmelose sodium and mixed well for $20 \mathrm{~min}$. The colloidal silicon dioxide and the talc were sieved and blended with the granulate for three minutes. The blended was compressed by using $6 \mathrm{~mm}$ round flat face bevel

TABLE 1. Composition (mg) of Mosapride citrate tablet formulations.

\begin{tabular}{lcc}
\hline Name of ingredient & Formulation & Formulation \\
Mosapride Citrate & A & B \\
Poloxamer 407 & 05.3 & 05.3 \\
Avicel PH 101 & 03.0 & - \\
Avicel PH 102 & 60.0 & 60.0 \\
Crosscarmelose sodium & 05.0 & 20.0 \\
Sodium starch & 05.0 & 05.0 \\
glycolate & 00.6 & 05.0 \\
aerosil 200 & 01.1 & 03.6 \\
Talc & 100 & 01.1 \\
Total weight (mg) & & 100 \\
\hline
\end{tabular}

edge tooling. Target weight and hardness were $100 \mathrm{mg}$ and $4-5 \mathrm{Kp}$, respectively[10].

\section{Characteristics of tablet formulations}

Weight, hardness, disintegration, friability, content uniformity of dose and dissolution profile of tablets were characterized. The average weight was recorded over 20 minutes, as recommended by the United States Pharmacopeia (U.S.P), 2006. 
The hardness was measured in a Tianjin Guoming Medicinal Equipment Co., Ltd. Hardness Tester (YD-3) over 10 tablets. The friability was tested for each formulation in a Tablet friability Tester for a sample of 20 tablets and the acceptance criterion was a maximum loss of $2 \%$ of initial weight (U.S.P. 2006). The disintegration was carried out in a disintegrator (Tianjin) (BJ2) and the time taken was compared with the acceptance criterion for a conventional tablet. The dissolution was carried out in a Schimadzu. The drug content of each batch was assayed by high performance liquid chromatography. Samples were analyzed on a Hewlett-Packard 1050 HPLC (Wilmington, DE) with UV detection at $274 \mathrm{~nm}$. Separation was performed on a STR BDS HYPERSILC18 - (4.6 x 250 $\mathrm{mm}$ ) or equivalent column with a mobile phase of phosphate buffer $(\mathrm{pH}=3.5)$, acetonitrile $(5: 5 \%)$, delivered isocratically $(1 \mathrm{~mL} / \mathrm{min})$ (Ciavarella USA Patent).

\section{Characterization methods}

The polymer nanocomposite films were analyzed using a Fourier transform infrared (FTIR) spectrophotometer Bruker Vertex 70 FT-IR in the attenuated total reflectance (ATR) mode. Aluminum substrates were utilized for FTIR analysis. The FTIR spectra were recorded from 4000 to $400 \mathrm{~cm}-1$ with a resolution of $4 \mathrm{~cm}$ 1 and an average of 16 scans. Powder X-ray diffraction patterns of the Mosapride-PXM 407 solid dispersions and their selected physical mixtures compared to the individual components were generated using Philips diffractometer (type PW-3710). The instrument was operated on the $2 \theta$ scale at room temperature.

\section{Dissolution assay}

Tablet dissolution was assessed in a standard USP 24 apparatus II (paddle) in $900 \mathrm{~mL}$ of $0.1 \mathrm{~N}$ $\mathrm{HCl}$ maintained at $37 \pm 0.5^{\circ} \mathrm{C}$. The speed of stirring was $100 \mathrm{rpm}$. In the test, the total of 6 tablets was used. Samples were taken at wide range of time from 5 to $60 \mathrm{~min}$. The dissolution medium was replenished after the collection of each sample with the same volume of fresh medium and analyzed for the percent release of drug by HPLC. A calibration curve was generated from HPLC chromatograms of standard solutions[11].

\section{Stability study}

The tablets were exposed to $40^{\circ} \mathrm{C} / 75 \%$ relative humidity for 1,2 and 3 months. After that, tablets were withdrawn at these times to analyze properties such as color, water content, dissolution, assay etc. [12].

\section{Results and Discussion}

\section{Preparation of mosapride-loaded tablets}

Table 2 shows blends of excipients and active drug were prepared and evaluated for the various parameters. In the range of 36.09 to $35.18^{\circ}$, angle of repose of all formulation batches from $\mathrm{A}$ to $\mathrm{B}$ was found. On another hand, the range from 0.343 to $0.340 \mathrm{~g} / \mathrm{cm} 3$ bulk density of formulation batches A to B was obtained while in the range of 0.378 to $0.379 \mathrm{~g} / \mathrm{cm} 3$ Tapped density was observed. According to the data were obtained compressibility index and Hausner's ratio were calculated for bulk and tapped density for formulation batches A to $\mathrm{B}$. The range of 9.817 to $9.995 \%$ was found for compressibility index and Hausner's ratio was obtained in the range of 1.103 to 1.111 . The data were obtained for compressibility index and hausner's ratio for all batches, better flow properties of powder blends of drug and excipients was indicated.

As shown earlier in Table 1, tablets of all formulation batches A were prepared by wet granulation technique while formulation batch B

TABLE 2. Evaluation of Powder Blends of formulation Batches.

\begin{tabular}{lcc}
\hline Evaluation Parameters* & $\begin{array}{c}\text { Formulation } \\
\text { A }\end{array}$ & $\begin{array}{c}\text { Formulation } \\
\text { B }\end{array}$ \\
\hline Angle of Repose $(0)$ & $36.09 \pm 0.784$ & $35.18 \pm 1.088$ \\
Bulk Density $\left(\mathrm{g} / \mathrm{cm}^{3}\right)$ & $0.343 \pm 0.002$ & $0.340 \pm 0.003$ \\
Tapped Density $\left(\mathrm{g} / \mathrm{cm}^{3}\right)$ & $0.378 \pm 0.002$ & $0.379 \pm 0.003$ \\
Compressibility Index $(\%)$ & $9.817 \pm 0.400$ & $9.995 \pm 0.967$ \\
Hausner's Ratio & $1.103 \pm 0.016$ & $1.111 \pm 0.011$ \\
\hline All values are mean $\pm \mathrm{SD}$. & &
\end{tabular}

TABLE 3. Evaluation of compressed tablets for formulation batches.

\begin{tabular}{|c|c|c|}
\hline $\begin{array}{l}\text { Evaluation } \\
\text { Parameters* }\end{array}$ & $\begin{array}{c}\text { Formulation } \\
\text { A }\end{array}$ & $\begin{array}{c}\text { Formulation } \\
\text { B } \\
\end{array}$ \\
\hline Weight. Variation $( \pm \%)$ & $1.247 \pm 0.942$ & $0.816 \pm 0.707$ \\
\hline Hardness $\left(\mathrm{Kg} / \mathrm{cm}^{2}\right)$ & $4.03 \pm 0.0577$ & $4.06 \pm 0.076$ \\
\hline Thickness (mm) & $2.88 \pm 0.0288$ & $2.81 \pm 0.0288$ \\
\hline Friability (\%) & $0.506 \pm 0.040$ & $0.61 \pm 0.050$ \\
\hline Disintegration (min) & $2.1 \pm 0.6022$ & $2.4 \pm 0.7985$ \\
\hline Drug Content (\%) & $101.37 \pm 0.248$ & $100.08 \pm 0.723$ \\
\hline $\mathrm{DP}_{60}(\%)$ & $99.81 \pm 1.431$ & $61.36 \pm 1.005$ \\
\hline
\end{tabular}

Egypt. J. Chem. 60, No.3 (2017) 
was prepared by direct compression technique. All of tablets were obtained in a uniform weight with acceptable variation because of the better flow properties of all batches.

Formulation batch A was comprised of avicel PH 101 as filler along with two different super disintegrants croscarmellose sodium (Ac-DiSol), and sodium starch glycolate (Primojel) with $5 \%$ concentration and PXM 407 as solubilizing agent, while formulation batch $\mathrm{B}$ was comprised exactly like that of batch A but without PXM 407. Tablets with PXM 407 showed a greater improvement in dissolution compared to that one without it. The reason of this behavior: with increasing the concentration of surfactant the micellar concentration was increased, as micellar concentration increased the rate of release of the drug was improved corresponding to the fast absorption of the dissolution medium by tablets and growing disintegration, which enhances the drug release. Therefore, it could be concluded that the surfactant was improved solubility and dissolution of drug.

Moreover, as shown in Table 3, Hardness and thickness of formulation batches $\mathrm{A}$ and $\mathrm{B}$ were found in the range of 4.03 to $4.06 \mathrm{Kg} / \mathrm{cm}^{2}$ and 2.81 to $2.88 \mathrm{~mm}$. Friability falls were observed at 0.506 to $0.61 \%$, respectively, indicating a good mechanical resistance of tablets was obtained. Drug content of formulation batches A and B was calculated at 100.08 to $101.37 \%$. Disintegration time of all formulation batches was found at 2.1 and $2.4 \mathrm{~min}$, respectively.

Tablets containing sodium starch glycolate (primojel) upon disintegration were generated with relatively high fragments which have a big size to pass through screen of disintegration vessel. However, large fragments were obtained still containing sodium starch glycolate. Croscarmellose Sodium (Ac-Di-Sol) was disintegrated tablets into relatively fine particles. Results were supposed that the super disintegrants were added into tablet formulations might be caused that penetration of water through the tablet; therefore, penetration rate of water would be altered. Moreover, the addition of the disintegrant having a property of fast water uptake in the formulation would be preferable to shorten the disintegration times in the tablet.

\section{FTIR-ATR analysis}

FTIR investigated the chemical composition

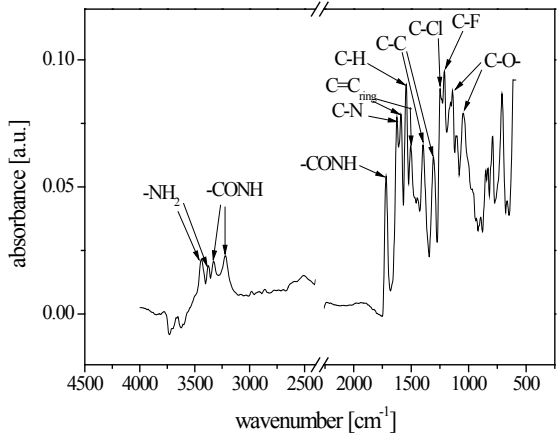

Fig. 2. IR patterns of Mosapride citrate.

of mosapride citrate involved in the complexation and more evidence of complex formation was observed. The FTIR spectra of binary systems which prepared by wet granulation in comparison to pure components are shown in Fig. 2, 3 and 4.

Figure 2 reveals the spectrum of Mosapride

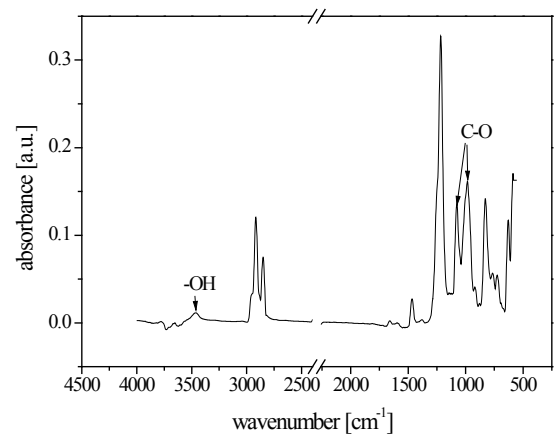

Fig. 3. IR spectra of Poloxamer.

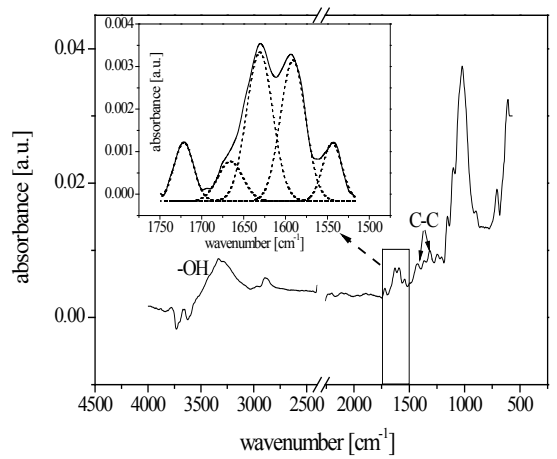

Fig. 4. FTIR spectra of Mosapride citrate-Poloxamer binary mixtures. The inset shows the stretching vibration of the carbonyl group $(\mathrm{C}=\mathrm{O})$ in the range from 1750 to $1520 \mathrm{~cm}^{-1}$ which deconvoluted into five components. The solid line represents the experimental data. The dashed lines represent the individual contributions. 
citrate and showed two characteristic forked absorption band at 3443 and $3379 \mathrm{~cm}^{-1}$ can be assigned to $-\mathrm{NH}_{2}$ stretching vibration and another one absorption band at $3334,3226 \mathrm{~cm}^{-1}$ related to tertiary amine $(-\mathrm{CONH})$ stretching vibration $[13,14]$.

Additionally, a characteristic absorption band at $1723 \mathrm{~cm}^{-1}$ may be assigned to the carbonyl amido (-CONH) stretching vibration. Other bands appeared at $1249 \mathrm{~cm}^{-1}$ (C-Cl stretching), 1216 $\mathrm{cm}^{-1}$ (C-F stretching), 1625 (C-N stretching), $1546 \mathrm{~cm}^{-1}(\mathrm{C}-\mathrm{H}$ stretching) and 1600 and 1500 $\mathrm{cm}^{-1}(\mathrm{C}=\mathrm{C}$ ring $)[15,16]$.

Furthermore, bands at $1329,1419 \mathrm{~cm}^{-1}$ might correspond to $\mathrm{C}-\mathrm{C}$ groups[17] and the $v \mathrm{C}-\mathrm{O}$ vibration was observed at $\sim 1047 \mathrm{~cm}^{-1}[18,19]$. The samples contained a band at $1465 \mathrm{~cm}^{-1}$ as might be expected that could be assigned to the deformation mode of $\delta \mathrm{CH}_{2}$ and also to methyl groups $\left(\delta \mathrm{CH}_{3}\right)$ was identified at $1347 \mathrm{~cm}^{-1}$. The obtained bands at $1207 \mathrm{~cm}^{-1}$ and $1151 \mathrm{~cm}^{-1}$ may be described as $\vee \mathrm{C}-\mathrm{O}$ of hydroxyl and $\mathrm{C}-\mathrm{O}$ groups, respectively[20-22]. The band of the mono-substituted aromatic ring at $700 \mathrm{~cm}^{-1}$ and those at 758,841 and $905 \mathrm{~cm}^{-1}$ is interpreted to ortho, para and meta out-of-plane deformation bending disubstitution, respectively[23] .

On the other hand, the spectra exhibit the $\mathrm{O}-\mathrm{H}$ and $\mathrm{C}-\mathrm{H}$ stretching vibrations are characteristic for Poloxamer, such $v \mathrm{O}-\mathrm{H}$ stretching vibration was detected at $\sim 3400 \mathrm{~cm}^{-1}$ and the $\mathrm{C}-\mathrm{H}$ vibrations: vas $\mathrm{CH}_{3}$ at $\sim 2960 \mathrm{~cm}^{-1}$, vas $\mathrm{CH}_{2}$ at $\sim 2929 \mathrm{~cm}^{-1}$, vs $\mathrm{CH}_{3}$ at $\sim 2880 \mathrm{~cm}^{-1}$ and the vs $\mathrm{CH}_{2}$ at $\sim 2850 \mathrm{~cm}^{-1}$ were showed (Fig. 3). The bands were observed at $1217 \mathrm{~cm}^{-1}$ and $1050 \mathrm{~cm}^{-1}$ were described as $v \mathrm{C}-\mathrm{O}$ of hydroxyl and other $\mathrm{C}-\mathrm{O}$ groups[17]. Moreover, the samples contained spectra at $1475 \mathrm{~cm}^{-1}$ that might be attributed to the $\delta \mathrm{CH}_{2}$ as might be expected like that observed in Mosapride structure.

In this work the characteristic bands of Mosapride such as $\left(-\mathrm{NH}_{2}\right)$ and $(-\mathrm{CONH})$ stretching in all the prepared systems by the broad intense band corresponding to the free- $\mathrm{OH}$ vibration (3500$3200 \mathrm{~cm}^{-1}$ ) (Fig. 4) were overlapped. In addition, the carbonyl stretching of the drug at $1721 \mathrm{~cm}^{-1}$ and the band corresponding to the hydrated bonds within PXM molecules at $\left(1750-1650 \mathrm{~cm}^{-1}\right)$ there is an overlap was observe[24].

To analyze the spectra quantitatively the following procedure is employed where five Gaussians were fitted to the data and regression coefficient was better than 0.99 . The inset of Fig. 4 gives an example for this procedure.

Therefore, the characteristic stretching bands of $(-\mathrm{CONH})$ and the carbonyl stretching $(-\mathrm{C}=\mathrm{O})$ of Mosapride citrate at $\sim 1721 \mathrm{~cm}^{-1}$ are the main characteristic bands were used to assess the drugPXM interactions. The doublet band of nearly equal to 1590 and $1620 \mathrm{~cm}^{-1}$ indicated to the $v_{\text {ring }}$ (the inset of Fig .4) [16,25].

The FTIR spectra of all mixing and the kneading products did not show any significant changes in comparison to the pure components.

On the other hand, the spectra of the drying products exhibited a broadening and intensity of the characteristic Mosapride carbonyl stretching band was decreased. The reason for the broadening and decrease of intensities of the drug carbonyl stretching band observable in these systems is probably because of its restriction within the PXM cavity[10].

\section{X-Ray Diffraction Analysis}

The X-ray diffraction pattern for pure drug and its binary systems were represented in Fig. 5, 6 and 7, respectively. Sharp peaks at a diffraction

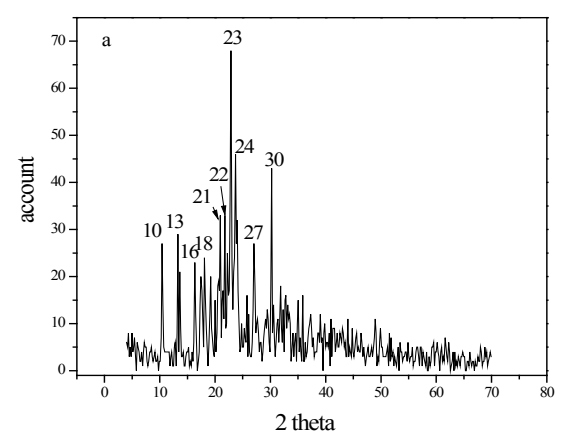

Fig. 5. X-ray diffraction patterns for the Mosapride.

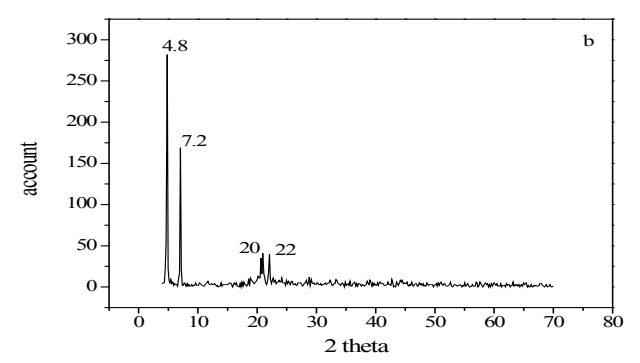

Fig. 6.X-ray diffraction patterns for the Poloxamer-407. Egypt. J. Chem. 60, No.3 (2017) 
angle $(2 \theta)$ of $\sim 10,13,16,18,21,22,23,24,27$ and $30^{\circ}$ with high peak intensities were showed for pure Mosapride sample (Fig. 5) indicating its crystalline form, while PXM-407 copolymer produced four characteristic peaks at 4.8, 7.2, 20 and $22^{\circ}$ (Fig. 6).

The intensities of the major drug peaks of Mosapride were slightly decreased in physical mixture Mosapride-Poloxamer 407, but the most of drug peaks were disappeared in all different solid dispersion systems.

Typical drug crystalline peaks were still detectable while reduced intensity and less number of peaks indicating that reduced

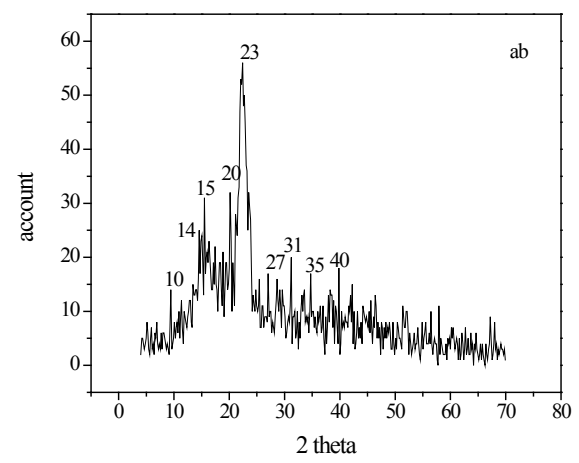

Fig. 7. Powder X-ray diffraction of Mosapride solid dispersion with Poloxamer 407.

crystalline nature of dispersion was obtained or that decreasing of the intensity due to the dilution effect of the carrier. However, the disappearance of the characteristic peaks of drug may be because of partially changes of materials from crystalline into amorphous one (Fig.7).

This confirms that in solid dispersion form, crystallinity of drug and polymer is reduced and it may contribute to the enhancement of dissolution of the drug [2].

In generally well known that in an amorphous form, drug in a solid dispersion system often exists. Thermodynamic activity is higher in the amorphous form of the drug than its crystalline form, leading to improve the solubility[12]. Similarly, such improving was due to the change of crystallinity to the amorphous form in the Mosapride-loaded solid dispersion.

Moreover, Mosapride dispersed in carriers may achieve the highest levels of particle size reduction and surface area enhancement [26-28] .

\section{Dissolution of drug-loaded tablets}

Drug dissolution as an integral part of drug product development was tested also as a quality control tool to monitor batch-to-batch consistency of the drug release from a product was used[29]. It is reasonable to have an in vitro method of testing dissolution that is sensitive to formulation factors that affect the solubility process and therefore, bioavailability. In recent years, the discriminatory capabilities and reliability of dissolution tests of tablets have attracted much attention[30]. In order to establish acceptance criteria and preview how alterations in manufacturing would affect

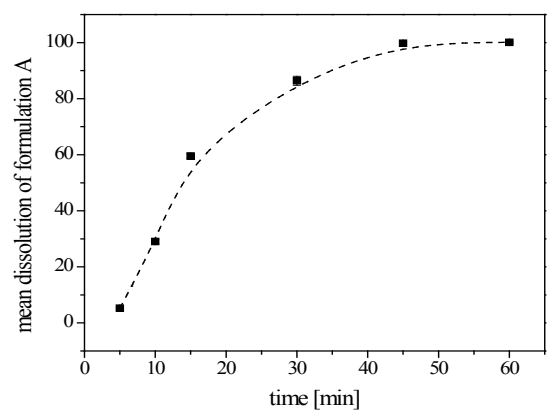

Fig. 8. Mean dissolution profiles of Mosapride tablets (Batch $\mathrm{A}$ ) at $\mathbf{4 0}^{\circ} \mathrm{C} / 75 \% \mathrm{RH}$. The error bars result from six tablets at the same formulation.

bioavailability, different parameters were used to differentiate and identify the differences in formulations.

From the good results obtained with formulation batch $\mathrm{A}$, it could be concluded that PXM 407 is the surfactant of choice for development of Mosapride Tablet (Table 3 and Fig. 8). This choice was confirmed by the stability study in which the formulation batch (A) tablets fully met the specifications. In the stability study, batch (A) tablets showed the expected hardness, disintegration time and moisture content throughout the 3-month period. Also, the dissolution rate (over $98 \%$ in $45 \mathrm{~min}$ ) and assay $(100 \%)$ remained good until the end of study (Fig. 9).

Therefore, this product might be kept for a period of one year or more, but further stability studies up to 6 months will be needed to determine the exact shelf life. 


\section{Conclusion}

For enhancing dissolution of medicine, the physicochemical properties of it are the crucial for determining the most effective strategy. Addition of surfactant is one of these strategies to improve the solubility of medicine. Therefore, PXM 407 was a good choice for development of Mosapride

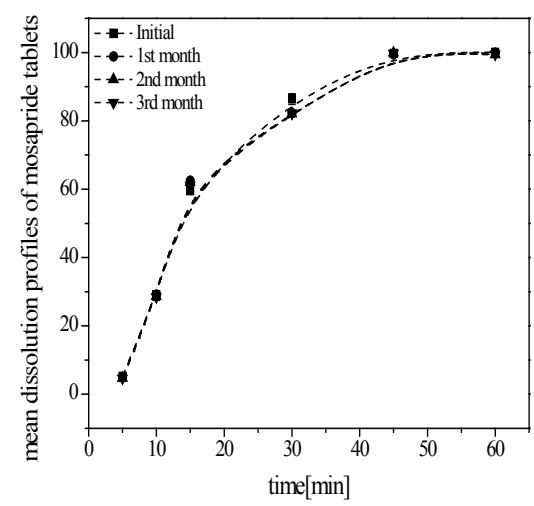

Fig. 9. Dissolution profiles of Mosapride tablets (Batch A) after $1,2 \& 3$ months at $40^{\circ} \mathrm{C} / 75 \% \mathrm{RH}$.

tablet. Batch (A) tablets showed the expected hardness, disintegration time and moisture content throughout the 3-month period. Moreover, the dissolution rate was over $98 \%$ in $45 \mathrm{~min}$. The in vitro dissolution must serve as both a quality control tool and a potential surrogate marker of medicine bioavailability and bioequivalence.

\section{References}

1. Bergström, C.A., Holm,R., Jørgensen,S.A.Andersson, S.B., Artursson,P., Beato, S., Borde,A.,Box, K., Brewst er,M.,Dressman,J.,Feng,K.I,Halbert,G., Kostewicz,E., McAllistar,M.,Muenster, U. Thinnes,J. ,Taylor,R., Mullertz,A. Early pharmaceutical profiling to predict oral drug absorption: current status and unmet needs, Eur J Pharm Sci. 57, 173-199 (2014).

2. Sheth,P., Sandhu,H., Singhal, D., Malick,W.,Shah,N., Kislalioglu, M.S. Nanoparticles in the pharmaceutical industry and the use of supercritical fluid technologies for nanoparticle production. Curr Drug Deliv., 3, 269284 (2012).

3. Saritha, A. Shastri, N. Preparation, physico chemical characterization of solid dispersions of tenoxicam with poloxamer, J. Pharmaceutical Sci. Technol. 2 (9), 308-311 (2010).

4. Vyas,V. Sanjeti,P.K. Kurekar,P. Kurekar,M. Shah,M. Physico chemical characterization of solid dispersion system of tadalfil with poloxamer 407 ,
Acta pharm. 59, 453- 461 (2009).

5. Basu,B., Bagadiya,A., Makwana,S.,Vipul,V., Batt, D., Dharamsi, A. Formulation and evaluation of fast dissolving tablets of cinnarizine using superdisintegrant blends and subliming material. $J$ Adv Pharm Technol Res. 4, 266-273 (2011).

6. Fukazawa,K., Furuta, K., Adachi,K., Moritou,Y., Saito,T., Kusunoki, R., Uno, G., Shimura, S., Aimi,M., Ohara, S., Ishihara,S., Kinoshita, Y. Effects of mosapride on esophageal motor activity and esophagogastric junction compliance in healthy volunteers. J. Gastroenterol. 49, 1307-1313 (2014).

7. W. Li, P. Quan, Y. Zhang, J. Cheng, J. Liu, D. Cun, R. Xiang, L. Fang, Influence of drug physicochemical properties on absorption of water insoluble drug nanosuspensions. Int J Pharm. 460, 13-23 (2014).

8. A. Nokhodchi, Y. Javadzadeh, M. Reza, J.M. Barzega, The effect of type and concentration of vehicles on the dissolution rates of a poorly water soluble drug indomethacin from liquisolid compacts. J. Pharm. Pharm. Sci. 8 (1), 18-25 (2005).

9. Chen,Y., Zhang, G.G.Z., Neilly, J., Marsh, K. Mawhinney, D., Sanzgiri, Y.D. Enhancing the bioavailability of ABT-963 using solid dispersion containing pluronic F-68, Int. J Pharm. 286, 69-80 (2004).

10. Cho, K. H.,Choi, Y. K., Kang, J. H., Choi, H-G., Yong,C. S., Park,Y-J. Development of a novel combination tablet containing trimebutine maleate and mosapride citrate for the treatment of functional dyspepsia, Int. J. Pharmaceutics 400, 145-152 (2010).

11. Yousaf, A. M., Jee,J-P. , Hwang, S. R., Maeng, H-J., Park, Y-J.,Kim, J. O.,Yong, C. S., Choi, H-G., Cho, K. H. Development of direct compression entecavir $0.5 \mathrm{mg}$-loaded tablet exhibiting enhanced content uniformity, Powder Technol. 267, 302-308 (2014).

12. Kima, Y-II., Kim, K.S., Suh, K-H., Shanmugam,S., Woo, J.S., Yong, C.S.,Choi, H-G. New clopidogrel napadisilate salt and its solid dispersion with improved stability and bioequivalence to the commercial clopidogrel bisulphate salt in beagle dogs, Int. J Pharmaceutics, 415, 129- 139 (2011).

13.Ficarra, R. Ficarra, P. Di Bella, M.R. Raneri, D. Tommasini, S. Calabrò, M.L. Villari, A. Study on the inclusion complex of atenolol with $\beta$-cyclodextrin. J Pharm Biomed Anal, 23, 231-236 (2000). 
14. Lopes, T. D., Riegel-Vidotti, I. C. ,Grein,A., Tischer, C. A., Faria-Tischer,P. C. S. Bacterial cellulose and hyaluronic acid hybrid membranes: Production and characterization, Int. J. Biological Macromolecules 67, 401-408 (2014).

15. Fahmy, A., Friedrich, J. Degradation behavior of thin polystyrene films under exposure to Ar-Plasma and its emitted radiation, J Adhesion Sci. Technol., 27, 324-338 (2013).

16. Federico, S., Nöchel,U., Löwenberg,C., Lendlein, A., Neffe, A. T. Supramolecular hydrogel networks formed by molecular recognition of collagen and a peptide grafted to hyaluronic acid, Acta Biomaterialia, 38, 1-10 (2016).

17. Kamoun, E.A., Youssef, M.E., Abu-Saied, M.A. Fahmy, A. Khalil,H.F. Abdelhai,F. Ion conducting nanocomposite membranes based on PVA-HAHAP for fuel cell application: II. Effect of modifier agent of PVA on membrane properties', Int. J. Electrochem. Sci., 10, 6627-6644 (2015).

18. Fahmy, A.,Schönhals,A. Reaction of $\mathrm{CO} 2$ gas with (radicals in) plasma polymerized Acrylic Acid (and formation of $\mathrm{COOH}$-rich polymer layers), Plasma Processes and Polymers 13, 499-508, (2016).

19. Del Fanti,N.A. Infrared spectroscopy of polymers. Madison, WI: Thermo Fisher Scientific; 2008.

20. Fahmy, A., Schönhals, A., Friedrich,J. Reaction of water with (radicals in) plasma polymerized allyl alcohol (and formation of OH-rich polymer layers), J. Physical Chemistry B, 117, 10603-10611 (2013).

21. Fahmy, A., Friedrich, J., Poncin-Epaillard, F., Debarnot, D. Plasma Polymerized Allyl Alcohol/O2 Thin Films Embedded with Silver Nanoparticles, Thin Solid Films, 616, 339-347 (2016).

22. Alemdar, N. Fabrication of a novel bone ashreinforced gelatin/ alginate/ hyaluronicacid composite film for controlled drug delivery,
Carbohydrate Polymers, 151, 1019-1026 (2016).

23. Fahmy, A., Mix, R., Schönhals, A., Friedrich, J. Surface and bulk structure of thin spin coated and plasma-polymerized polystyrene films, Plasma Chem Plasma Process, 32, 767-780 (2012).

24. Fahmy,A., Eisa, W. H., Yosef, M., Hassan, A. Ultra-thin films of poly(acrylic acid)/silver nanocomposite coatings for antimicrobial applications, J. Spectroscopy 2016, 11, (2016).

25. Fahmy, A., Kamoun, E. A., Elessawy,R., ElDamhougy,B. K., El-Fakharany, E. M., Abdelhay, F. Poly(vinyl alcohol)-hyaluronic acid membranes for wound dressing applications: Synthesis and in vitro bio-evaluations, J. Brazilian Chem. Society, 26, 1466-1474 (2015).

26. Oh,D.H., Park,Y.-J., Kang,J.H., Yong, C.S., Choi, H.G. Physicochemical characterization and in vivo evaluation of flurbiprofen-loaded solid dispersion without crystalline change. Drug Deliv. 18, 46-53 (2011).

27. Park, J.Y. ,Kim, K.A., Ryu, J.H., Lee, G.H., Jeon,S.H., Kim, J.S. Pharmacokinetics and the antiplatelet effect of a new clopidogrel formulation, clopidogrel besylate, in healthy subjects. Int. J. Clin. Pharmacol. Ther. 48 (4), 259-269 (2010).

28. Park,Y.J., Xuan, J.J.,Oh D.H., Balakrishnan, P. ,Yang,H.J., Yeo, W.H., Lee, M.J., Yong, C.S., Choi, H.G. Development of novel itraconazole-loaded solid dispersion without crystalline change with improved bioavailability. Arch. Pharm. Res. 33 (8), 1217-1225 (2010).

29. Uppoor,V.R. Regulatory perspectives on in vitro (dissolution)/in vivo (bioavailability) correlations, J Control Release. 72 (1-3), 127-132 (2001).

30.Rachid,O.,Rawas-Qalaji,M.,Simons,E.R. ,Simons,K.J.Dissolution testing of sublingual tablets: A novel in vitro method. AAPS Pharm Sci Tech. 12(2), 544-552 (2011). 
تأثير مادة Poloxamer على خو اص التحلل لمادة Mosapride وكذلك تكوينه قرص علاجى

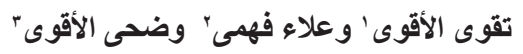

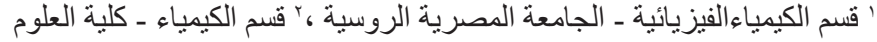

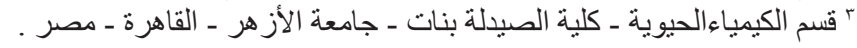

در اسة الخصائص الفيزيائية و الكيميائية للاو اء أمر حاسم لتحديد الاستر اتيجية الأكثر فعالية ودر اسة هدى امكانية

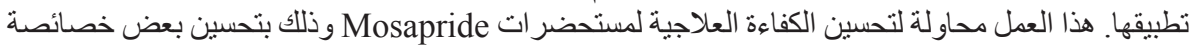

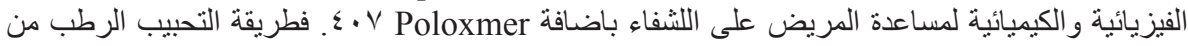

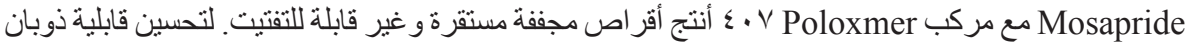

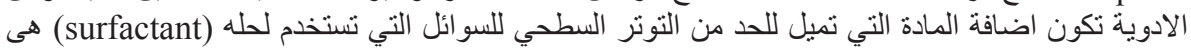

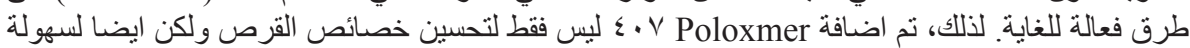

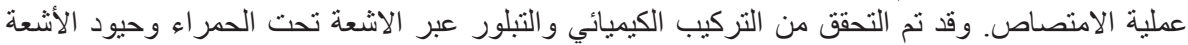

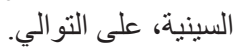

